EL NUEVO TEMPLO MORMÓN EN WASHINGTON, D. C.

O NOVO TEMPLO MÓRMON EM WASHINGTON, D.C.

THE NEW MORMON TEMPLE IN WASHINGTON, D.C.

Mark P. Leone

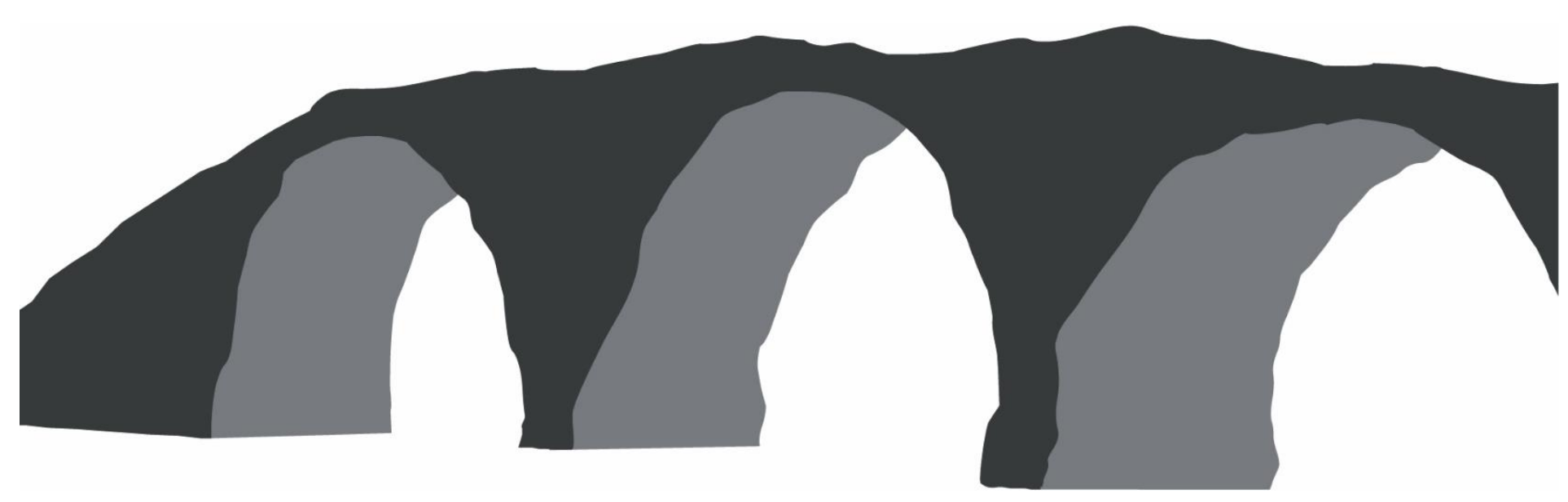




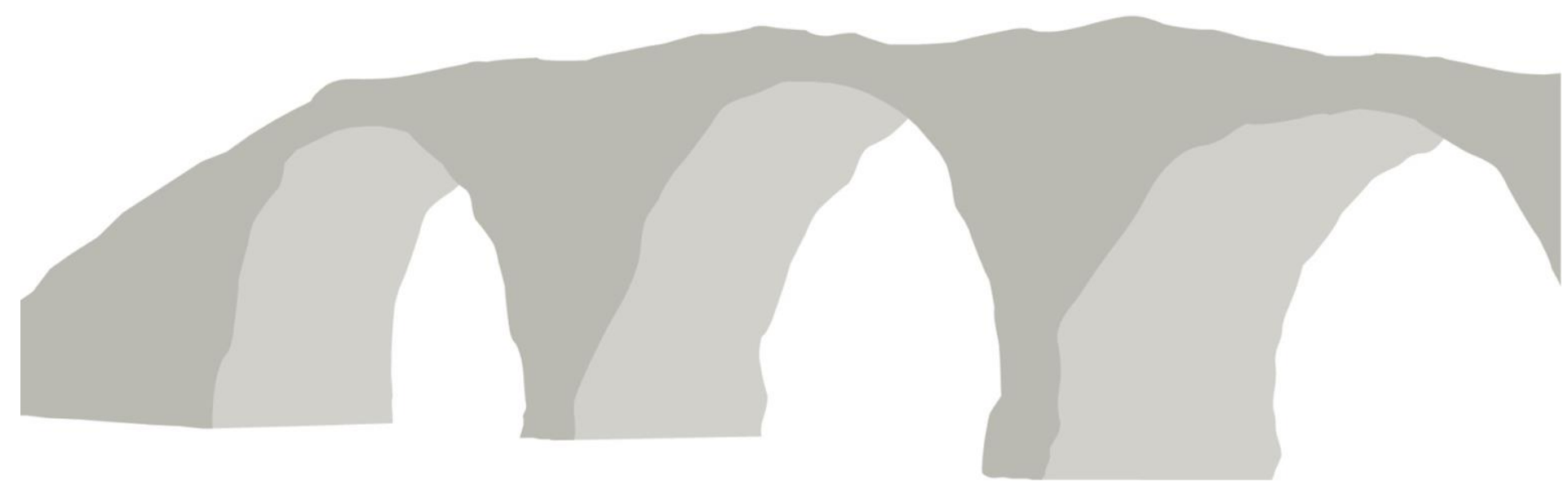

Publicação original:

Leone, M. (1977). The New Mormon Temple in Washington, D. C. In Historical Archaeology and the Importance of Material Things. Historical Archaeology. Special Publication Series 2:43-61. Reprinted in Sunstone (a Mormon journal), SeptemberOctober, 1978.

Traduzido e publicado com permissão da Society for Historial Archaeology. Leone, M. (1977). The New Mormon Temple in Washington, D. C. In Historical Archaeology and the Importance of Material Things. Historical Archaeology. Special Publication Series 2:43-61. Reprinted in Sunstone (a Mormon journal), September-October, 1978. 


\title{
EL NUEVO TEMPLO MORMÓN EN WASHINGTON, D. C.
}

\section{O NOVO TEMPLO MÓRMON EM WASHINGTON, D.C.}

\section{THE NEW MORMON TEMPLE IN WASHINGTON, D.C. ${ }^{1}$}

\author{
Mark P. Leone ${ }^{2}$
}

\section{RESUMEN}

Este articulo tiene como objetivo discutir arqueológicamente la Catedral Mormona de Washington, construida por la Iglesia de Jesucristo de los Santos de los Últimos Días, en el condado de Montgomery, Maryland, Distrito de Columbia. Esta peculiar y sorprendente construcción refleja a través de su materialidad las aspiraciones e ideales mormones, que por su vez son exhibidos para el resto de la nación. A partir de un análisis estructural de su arquitectura, la arqueología crea herramientas para entender y generar interpretaciones sobre el universo mormón.

\section{RESUMO}

Este artigo tem como objetivo discutir arqueologicamente a Catedral Mórmon de Washington, construída pela Igreja de Jesus Cristo dos Santos dos Últimos Dias, no Condado de Montgomery, Maryland, Distrito de Columbia. Esta construção peculiar e surpreendente reflete as aspirações e ideais Mórmons por meio de sua materialidade, que por sua vez são exibidos para o resto da nação. A partir de uma análise estrutural de sua arquitetura, a arqueologia cria ferramentas para entender e gerar interpretações sobre o universo Mórmon.

\section{ABSTRACT}

This article aims to discuss archaeologically the Washington Mormon Cathedral, built by the Church of Jesus Christ of Latter-day Saints, in Montgomery County, Maryland, District of Columbia. This peculiar and surprising construction reflects Mormon aspirations and ideals through its materiality, that at the same time, are exhibited to the rest of the nation. From a structural analysis of its architecture, archeology creates tools to understand and generate interpretations about the Mormon universe.

\footnotetext{
${ }^{1}$ Traducido al español por Sandra A. Guillermo (A\&C Gestión, Investigación y Patrimonio, Ministerio de Cultura de la Nación). E-mail: sg.arqueologia@gmail.com. ORCID: https://orcid.org/0000-0003-1884-9814.

${ }^{2}$ University of Maryland. E-mail: mleone@anth.umd.edu.
} 
Este ensayo tiene solamente un objetivo real: explicar el nuevo templo, el Templo de Washington, construido por la Iglesia de Jesucristo de los Santos de los Últimos Días (los Mormones) en el condado de Montgomery, Maryland, justo sobre la línea estatal del Distrito de Columbia. Se trata de una peculiar y sorprendente construcción vista por cientos de millones de Americanos anualmente y construida por una Iglesia cada vez más prominente en la escena americana. La importancia del edificio mormón es lo que impulsa este artículo.

Yo quiero usar un simple análisis estructural para mostrar como encajan las piezas del templo tomadas en conjunto y de este modo adquieren sentido. Y mientras utilizamos un análisis estructural, a mí también me gustaría denominar a este esfuerzo como una pieza de arqueología histórica: histórica porque los mormones están alfabetizados, y de arqueología porque se intenta tratar una obra de cultura material en su contexto social más amplio. En tanto la naturaleza del ensayo, se lo puede llamar también historia del arte o análisis arquitectónico o simple etnografía, yo estoy interesado en llamarlo arqueología porque esto me permite a mí destacar el rol de la forma-construcción, como forma tridimensional- del comportamiento humano.

Cada uno de los periódicos importantes de la costa Este ha escrito notas sobre el nuevo templo. En su mayor parte en el otoño de 1974, pero en el área de Washington la atención estuvo focalizada durante varios años en el aumento del volumen de las imponentes nuevas construcciones sobre la carretera de circunvalación. La construcción es inmensa, es asombrosamente visible, y la atención ha sido, no por casualidad, proporcional a su creciente tamaño y visibilidad. Si bien la atención ha sido alta, la comprensión ha sido baja y las revisiones arquitectónicas lo han tratado como si fuese un nuevo centro de arte, un nuevo hotel - una referencia a la participación de la familia de hoteles Mariott (mormones) en la empresa- o como la más reciente excrecencia arquitectónica al ser parodiado por causas liberales y elegantes equivalentes a las de Tom Wolfe. No hay duda que el templo es un tema fértil y fue pensado para atraer la atención. No hay duda tampoco que no sigue muchos de los cánones de la arquitectura moderna. Hay incluso menos dudas que lo que sus constructores pretenden decir es escuchado débilmente por su audiencia, si es que lo escucha, en la medida en que esa audiencia consiste en no-mormones. Sería bueno, aunque algo incómodo, decir que los mormones construyeron el templo y comenzaron un diálogo con una población del Este y entonces nosotros seguimos el diálogo. Bueno, para ser certero ellos lo empezaron, pero mucha de la réplica inicial desde el otro lado fue un abuso carente de comprensión. Pero más allá de eso, el diálogo es peculiar porque los mormones agitan pero no hablan, indican, pero no explicitan, y aturden el ojo pero no el oído. Los turistas pasan por el templo sin guías y preguntando pocas cuestiones a personas que pueden dar solamente respuestas indirectas acerca de los usos del templo, los cuales deben, por juramento, permanecer secretos. Por su lado, la atención americana usualmente ve la construcción en pequeñas unidades íntimas, como el auto familiar que va por una carretera completamente sin compañía, identificando señales. Como resultado de todo esto, el templo ha comenzado una conversación con sus visitantes, mormones y no mormones, como si fuese una conversación de dos sordomudos sobre un elefante. Ambos saben que el objeto está allí pero no pueden hablar acerca de lo que eso significa para cada uno de ellos. Ninguno de los dos puede estar seguro que el otro conoce que el elefante es realmente blanco.

¿Por qué todo el silencio? Yo pienso que la respuesta se encuentra en la naturaleza del Mormonismo, y es obviamente esta naturaleza la que es más importante que el templo y se refleja en él. Pese a que parecería extraño considerar al Mormonismo, una religión misionera altamente pública como silenciosa, sin embargo, de una manera clave y central, lo es. Por encima de todo, es su capacidad para el silencio, para no integrar 
todas sus áreas en público, para mantener sus mundos privados, dejando que los gestos permanezcan sin ser interpretados y dejando que las ambigüedades resultantes permanezcan inalteradas, lo que resulta clave y central en su manera de pensar.

Una vez que esta manera de pensar se comprende, el significado y el silencio del templo quedan más claros. El método para describir este patrón de pensamiento implica examinar lo que Deetz y Glassie en este volumen llaman patrones cognitivos; lo que Erwin Panofsky (1955, p. 31) denomina valores simbólicos; e implica lo que la mayoría de nosotros conocemos directamente de Lévi-Strauss como estructura. Adicionalmente, esto es lo que los arqueólogos entienden como estilo. Además de usar la estructura o el estilo para entender este edificio, también quiero usar los actuales patrones del material con el que el templo está construido para ver cómo estos guían el comportamiento de las personas y, más efectivamente que las palabras, comunican la esencia del Mormonismo. Que el visitante no-mormón ni el mormón puedan articular los mensajes del templo no invalida la cuestión, pues las señales están allí al igual que la luz que lleva la blancura del elefante a los ojos del sordomudo.

Quiero iniciar este análisis citando a sus predecesores. En un breve e intrigante ensayo publicado recientemente, James Deetz (1974) habla acerca de algunas de las diferencias claves que caracterizan la cultura material de la Nueva Inglaterra colonial. Su distinción clave es entre una tradición temprana en Nueva Inglaterra, la cual fue esencialmente medieval y una posterior "mostrando el impacto del Renacimiento en la forma de la tradición Georgiana” (Deetz, 1974, p. 22). Usando la cultura material, Deetz diferenció en Nueva Inglaterra entre la Edad Media y el Renacimiento mostrando que la primera era una mezcla de todas las partes cada una incrustada en la otra, y la segunda se caracterizaba por la simetría bilateral y el aislamiento de partes individuales. La caracterización de Deetz de lo medieval en Nueva Inglaterra es particular e inductiva. Su interpretación del Renacimiento es más radical y estructural e ilustra mejor lo que él y Glassie quieren decir con un patrón cognitivo. Su visión del Renacimiento ilustra como una vasta cantidad de material puede ser organizado para ejemplificar un patrón clave de pensamiento que a su vez se encuentra en muchas facetas de toda cultura.

Este es el tipo de análisis que algunos historiadores del arte, algunos historiadores de la arquitectura y algunos historiadores de lo cultural han estado haciendo por algún tiempo. No es psicológico, sino más bien impresionista. Es bastante empírico, aunque al igual que con el estructuralismo en general, es difícil de refutar y, en consecuencia, difícil de probar. Su popularidad demuestra su utilidad en la medida en que la misma demuestra fortaleza. Yo personalmente pienso que ni Glassie ni Deetz han hecho mucho más que un trabajo impresionista en este tipo de análisis y, al no consultar las fuentes que podrían haber tenido, han perdido la posibilidad de alcanzar un nivel de generalidad sobre la Edad Media que ellos si alcanzaron para el Renacimiento. Ciertamente, una figura clave para establecer las diferencias críticas entre la Edad Media y el Renacimiento es Erwin Panofsky, quien en relación con la forma es más preciso, perceptivo y general. Al caracterizar la forma medieval, Deetz habla de una "relación asimétrica medieval entre los individuos y su cultura material...la comida no se consumía en piezas individuales (platos); los recipientes comunales parecieron ser la regla". Y, "cuando uno entra en una casa de origen medieval pre-georgiano, uno entra en toda la gama de actividades, desde la maternidad hasta cocinar, hacer artesanías y dormir, sucediendo todo en una sala" (Deetz, 1974, p. 23-24). Comparando esta descripción innegablemente precisa con Panofsky, quien, tomando todo lo anterior y todo el arte medieval en general, dice: “Aquellos a quienes les gusta interpretar hechos históricos simbólicamente [Deetz y Glassie usando Levi-Strauss dirían cognitivamente] pueden 
reconocer en [el arte renacentista]... una concepción específicamente "moderna" del mundo que permite al sujeto afirmarse frente al objeto como algo independiente e igual; mientras la antigüedad clásica no permitió la formulación explícita de este contraste; y mientras la Edad Media creía que el sujeto así como el objeto estaban sumergidos en una unidad superior" (Panofsky, 1955, p. 99). Lo que Deetz vio para el estilo medieval fue el individuo sumergido en la masa, pero lo que él no vio fue que las funciones estaban completamente absorbidas entre sí. El Renacimiento al crear simetría bilateral creó los platos de comedor individuales y separados, así como los famosos bacines de Deetz, pero también aisló funciones de modo que, como dice Deetz, "cuando uno entra por la puerta de una casa georgiana, uno ve puertas. Y cuando uno atraviesa esas puertas, es muy probable que vea aún más puertas antes de llegar a la actividad final que está sucediendo” (Deetz, 1974, p. 24).

Entonces para aclarar, sin estar en desacuerdo con Deetz, el patrón o estilo cognitivo de la Edad Media es "la repetición de la forma (rima en oposición a métrica) y el verticalismo" (Panofsky, 1955, p. 188) mientras que el del Renacimiento es la simetría bilateral. La Edad Media no separa al individuo, ni a la función, ni al tiempo; el Renacimiento inventó al individuo, distinguió las partes de la sociedad y descubrió la historia. En el descubrimiento renacentista de la perspectiva, que es un concepto espacial y atemporal, como Panofsky (1955, p. 51) ha señalado y como John Rowe (1965, p. 1-20) ha informado a los antropólogos, existe una visión segmentada del mundo que reside en la relación del hombre con el hombre, el hombre con el espacio y el hombre con el tiempo. Estas distinciones no solo no estaban disponibles o no fueron descubiertas en la Edad Media, sino que, además, resultaron en la teoría Renacentista de las proporciones que fue usada por artistas Renacentistas y que, cuando se impuso en la forma, dio como resultado la aparición de imágenes orgánicamente reales. Lo "real" fue creado a través del uso de una ilusión. La pintura fue la ilusión, la técnica utilizada para crear la ilusión fue la perspectiva, y la estructura o el estilo de la ilusión fue una forma particular de simetría: bilateral, en la que cada lado exhibe un patrón regular repetido de las partes componentes.

Fue con la perspectiva que lo individual pudo ser aislado del grupo o masa; que el tiempo pudo ser segmentado dando lugar a una de sus unidades, la historia; y el espacio dividido con cierta "precisión". Todo esto es lo que significa la simetría bilateral. Es lo que es inherente al estilo o estructura, y lo que es revelado por un estudio de los efectos de tal "patrón cognitivo" en una cultura.

El valor de este tipo de análisis estructural, iconológico o estilístico reside en la amplia aplicabilidad de la percepción a una gran cantidad datos de la época y la cultura. Obviamente, vinculando el arte elevado de Panofsky y los artefactos plebeyos de Deetz - se abarca toda forma material dentro de una sociedad, pero además puede ser prolíferamente aplicado a formas como música, danza, teatro, formas de organización social y, lógicamente, mitos. Como arqueólogos, nosotros estamos claramente preocupados por la cultura material y, como tal, la luz que Deetz y Glassie está enfocando sobre la disciplina con su trabajo destaca el problema que tradicionalmente hemos conocido como estilo. Al vincularse con Levi-Strauss, tanto Deetz como Glassie han identificado, sin darse cuenta, qué es estilo y nos han mostrado cómo analizarlo. Aunque el trabajo es impresionista y según los cánones de trabajo detallado de Levi-Strauss, deshecho, los beneficios que se pueden extraer son intrigantes, y dado que este ensayo también trata con un grupo alfabetizado, por no hablar de uno vivo, es útil intentar tal esfuerzo. 
LA IGLESIA DE JESUCRISTO DE LOS SANTOS DE LOS ÚLTIMOS DÍAS ha construido dieciocho templos desde Suiza a San Pablo y de Hawai a Nueva Zelanda. Para un mormón, el templo es lo más cercano al otro mundo que puede estar sobre la tierra. El templo es la residencia de Dios más que la capilla local donde hace la mayor parte de su culto y toda su reunión congregacional. Un mormón visita un templo una vez al año como un tipo de norma, pero puede ir todos los días, o varias veces en un año. También puede ir con mucha menos frecuencia que una vez al año. Pero no puede ser un buen mormón si evita el templo.

Los mormones pasan por una serie de ritos en el templo que les garantiza a ellos y a sus parientes, vivos y muertos, las recompensas que la iglesia promete en la próxima vida. Las ceremonias son largas y complejas, toman la naturaleza de los ritos de iniciación centrados en el individuo y su familia, y no se centran en el grupo o la congregación. Son los actos más sagrados y significativos que un mormón puede realizar.

Después de su inauguración, el templo permanece cerrado a todos los no-mormones y a cualquier mormón que no haya pagado el diezmo completo o que haya roto la Palabra de Sabiduría, la cual prohíbe fumar y tomar bebidas alcohólicas y con cafeína. Hay otros requisitos más generales acerca de la calidad de la fe, etc. Además, los ritos del templo son secretos; los mormones generalmente no los discuten fuera del templo en sí. Todo esto eleva la experiencia del templo hacia algo único y altamente inusual y hace que el templo sea un lugar de total seguridad, ya que en él el fiel mormón está en contacto con sus parientes fallecidos y su propio futuro. El tiempo se detiene en este edificio; o mejor, está comprimido. El tiempo está vencido.

Las series de ceremonias en el templo que aseguran el bienestar espiritual se dividen en tres categorías: (1) bautismo, (2) una serie de dramas rituales que desarrollan la historia espiritual del hombre y durante la cual los participantes reciben cualidades que son dones del Espíritu Santo con respecto a la admisión y el comportamiento en la esfera más exaltada de la próxima vida, y (3) el sellado, durante el cual los parientes vivos y muertos se unen entre sí por toda la eternidad.

En estas ceremonias, que están disponibles para cualquier mormón que cumpla con los requisitos para ingresar al templo, están participando unidades familiares y para llevar familias allí frecuentemente, todo un grupo de miembros de la comunidad (asociados a una parroquia) pasarán por el templo el mismo día, aunque no necesariamente pasarán a través de alguna o todas las ceremonias juntos. Un templo como el nuevo en Washington tendrá un horario complejo, y para todos los mormones a los que sirve en la costa Este, el este de Canadá y el Caribe, se reservará varias veces durante el año cuando específicas comunidades planifiquen enviar miembros. Dado que toma varias horas atravesar todos los ritos del templo y dado que un templo puede servir a una población de cien mil personas, estas construcciones frecuentemente operan tanto de noche como durante el día.

Cada templo tiene un presidente, un vasto staff formado por voluntarios locales que actúan como guías, instructores y trabajadores para su funcionamiento. Un templo como el de Washington tiene una cafetería para trabajadores, una lavandería para las prendas especiales que se requieren durante los ritos y todo un personal de apoyo para mantener la autosuficiencia mientras opera.

El diseño y la distribución del nuevo templo son notables: se eleva muy por encima de lo habitual o convencional en la arquitectura de una iglesia y proporciona una de las claves para una comprensión literal y simbólica de la naturaleza de los ritos del templo. En contraposición a la expectativa de la mayoría de los laicos, el templo no es un gran espacio abierto para el culto grupal como una catedral. Más bien se compone de siete pisos, seis de los cuales se dividen en muchas pequeñas cámaras ceremoniales. El piso superior, el séptimo, es un salón único llamado Salón de la Asamblea Solemne; es esencialmente un auditorio y casi nunca se utiliza. 
No figura en los ritos del templo y la mayoría de los mormones nunca lo visitan. No todos los pisos en el Templo de Washington están diseñados de la misma manera, pero varios de los más importantes ceremonialmente están divididos en seis salas en forma de pastel vinculadas por un corredor que las rodea a lo largo de la pared del edificio. La planta básica del templo es hexagonal y esta planta se sigue en algunos pisos interiores de modo que seis salas más o menos triangulares dividen eficientemente el espacio de un piso. Estas salas no parecen vincularse entre sí, pero desembocan en el corredor circunferencial que las une a todas.

Los muchos pisos están vinculados por dos escaleras monumentales en cada extremo del edificio; estas ascienden a través de las dos torres principales en cada punto extremo del templo. Los ascensores también hacen el mismo trabajo y al lado de cada uno en el piso apropiado hay un mapa hexagonal del piso en el que uno está, mostrando las salas ceremoniales numeradas con luces detrás para que el espectador pueda ver a simple vista cuáles están ocupadas por los ritos en curso. Cuando se está atravesando el templo uno tiene la impresión de un vasto conjunto de salas dispuestas entre sí de una manera que no es del todo evidente. Yo pienso que la mejor manera de transmitir el efecto es decir que durante las visitas públicas en el otoño de 1974 quizás un centenar de personas fueron admitidas como grupo cada veinte o treinta minutos, lo que significaba que cientos de personas deambulaban por el edificio a su propio ritmo en cualquier momento. Sin embargo, a mitad de esta visita auto-guiada, fue difícil ver a otra persona. El edificio es tan grande y contiene tantas salas que simplemente absorbe a las personas. Era muy posible estar solo, alejado y tranquilo sin ver ni ser visto por otra persona. Estas observaciones son útiles, si son personales, porque ellas reflejan la naturaleza altamente individual y privada de la experiencia que los mormones tienen en este edificio. Está muy adaptado al yo y a lo idiosincrásico.

El individuo atraviesa el templo por sí mismo y es frecuentemente acompañado por parientes - esposo, esposa e hijos. Socialmente es una experiencia familiar en un sentido muy profundo porque los lazos familiares son los que dan permanencia eterna en el templo, pero espiritualmente y psicológicamente los mormones hablan acerca de la experiencia en términos profundamente personales; esto tiene su impacto más profundo en el individuo. Su propósito no es crear una unidad grupal o comunidad. El templo y sus ritos tienen que ver con el orden; ellos crean una línea continua de parientes que se remonta a través de otras épocas de la historia que de otro modo significarían menos personalmente, y lo hacen a través del bautismo indirecto por parientes muertos, y a través de investiduras y sellos que proyectan a la familia hacia el infinito. El templo garantiza el orden en la historia y reduce el futuro a una función de los actos realizados ahora. Dado que todos los ritos del templo usan el parentesco como base para la organización, cada participante es un yo que construye su mundo, para asegurarse una visión mágica de uno, en consecuencia. Un individuo hace esto por sí mismo solo una vez; todas las demás veces asume el yo de un pariente o incluso del pariente de otra persona.

Los mormones expresan esta interacción entre el individuo y el grupo, ya sea familia o iglesia, utilizando la imagen de una colmena. Joseph Smith inició este simbolismo, que alcanzó su apogeo durante el período de la iglesia de Utah en el siglo XIX. Deseret, el nombre del reino santo, significaba abeja melífera en "Egipcio Reformado", según el Profeta. La colmena con el lema "Industria" se convirtió en la imagen visual del Territorio de Utah y más tarde del estado. Brigham Young construyó su famosa Casa Colmena, su residencia oficial con una gran colmena tallada en la parte superior. La colmena expresaba la relación del individuo con el todo ordenado: el individuo puede realizarse solamente a través de su lugar en el conjunto. El simbolismo es muy antiguo en esta iglesia, es consciente y reconocido por todos los miembros, y ha sido elaborado en un momento u otro antes que todos los mormones. En consecuencia, no es un accidente ni una acción 
particularmente inconsciente que el nuevo Templo de Washington sea hexagonal, el patrón geométrico básico dentro de una colmena. Los templos, como las colmenas, construyen y demuestran orden, y el individuo que pasa por uno se muestra ordenado y tiene el poder de crear el mismo orden que presencia. Las imágenes de la colmena nos permiten ver la relación entre el individuo y el todo en el Mormonismo, una relación mucho más enfática, mucho más latente con el atomismo y patrocinando mucha más independencia e idiosincrasia de lo que usualmente nosotros vemos en las iglesias Cristianas. Aunque esto será más claro más adelante, he planteado las imágenes aquí para enfatizar el punto de que el templo asegura el orden pero lo hace para el yo en oposición al grupo.

El orden y la certeza de la colmena son enfatizados y parcialmente creados por la ubicación del templo. Para ir debe utilizarse la carretera de circunvalación y atravesar el tráfico de una de las carreteras más grandes, transitadas, más despersonalizadas y aterradoras del país. Un mormón, sin duda hablando por muchos otros, ha comentado sobre el "contraste entre el tráfico de Washington y la paz del templo". Es "como ir al cielo y volver de nuevo". El orden y la certeza del templo se destacan por la experiencia en la carretera donde se engendra la incertidumbre, la tensión, la inmediatez de un posible desorden y la falta casi total de contacto y preocupación por el prójimo. En consecuencia, el templo es aún más significativo porque representa la superación garantizada y porque el mormón puede ver una verdad que lo libera del mundo loco que acaba de atravesar y que debe, al enviarlo de regreso al mismo mundo, dejarlo cambiado y más fuerte. Esto le muestra al mormón su lugar individual dentro de la vida y más allá, y lo hace sumergiéndolo en el desorden a medida que se acerca al edificio y sumergiéndolo en el orden una vez que está en él.

Hasta ahora, este artículo ha sido una descripción del templo y su propósito para los mormones. Lo único logrado hasta este punto es que el templo no es un edificio de iglesia habitual. Parte de su rareza surge de (1) su énfasis sobre el individuo y su familia, más que en la congregación y (2) la relación del individuo con el orden. ¿Cómo es creado el orden?

Los mormones viven con éxito tanto en el mundo del caos externo como en el mundo del orden dentro de la iglesia. Nosotros podemos suponer que esto es así porque, entre otras razones, su experiencia en el templo les muestra y les enseña cómo hacerlo. Los éxitos mormones en los negocios, el gobierno, la administración y las finanzas son también bien conocidos como para que sea necesario relacionarlos aquí. Los mormones y el Mormonismo manejan el mundo real muy bien en sus propios términos. Dado que en los ritos del templo se participa del cielo ("cosas eternas"), lo trascendental y lo no empírico son las cosas más elevadas que un mormón vivo puede experimentar. Esto es desconcertante ante el éxito mundano de los mormones. Puede ser argumentado que muchos modernos cristianos son bastante exitosos en el mundo y creen en la transubstanciación, la eficacia de la oración y la realidad de la magia. Sin embargo, lo que los mormones experimentan en el templo es más personal, coherente, más envolvente y, yo quisiera indicar que, requiere un mayor salto de fe, precisamente por ser tan nuevo y no tradicional, tan infundado en la aceptación popular y tan abarcador. Los ritos del templo son extravagantemente sistemáticos abarcando la vida de un hombre. Se supone que afectan la vida de uno profundamente, y obviamente hacen eso a juzgar por lo que dicen los participantes. Estos son diferentes a la mayoría de los rituales cristianos, y por esta razón son más difíciles de compartimentar fuera de la existencia. Entonces la pregunta es: ¿Cómo pueden los mormones negociar ser mormón y estar en el mundo simultáneamente? Y la respuesta es: el éxito no se produce a pesar de la peculiaridad de los mensajes recibidos en el templo, sino por ellos. Y para ir un paso más allá, los mensajes sobre la próxima vida obviamente tratan de algo poco empírico, pero la forma en que se entregan esos mensajes 
es muy empírica y, de hecho, forman la base de lo que un mormón toma del templo para tratar con éxito la vida diaria. Hay una parte de la información general que un mormón toma del templo. Este es el conocimiento de su lugar como un individuo específico en la familia interminable.

Recordemos el silencio del templo (los mormones no pueden hablar de eso afuera ni siquiera entre ellos, y deben permanecer en silencio durante las ceremonias) y el énfasis en la meditación y la reflexión. La discusión en el templo suele ser con un cónyuge o hijo o hija. Las personas, sabiendo que están más cerca de Dios aquí, a veces tienen visiones y revelaciones, algo a lo que los mormones tienen derecho en relación con ellos mismos y sus familias. Las ceremonias son pequeñas y culminan en asegurar un lugar propio o de un familiar en la familia para la próxima vida. Todo ocurre en la multitudinaria inmensidad de este muy dividido y aislado edificio. No se hace hincapié en lo que está sucediendo para nadie más, en ningún otro lugar y, de hecho, no hay una forma real de averiguarlo. El individuo está solo (pero nunca realmente solo) con su familia y sus pensamientos. Se le anima a dedicar tiempo a los pensamientos para resolver problemas y preguntas de profunda preocupación para que pueda recibir iluminación. No hay discusión y ciertamente no hay verificación ni de las preguntas ni de las respuestas extraídas de las ceremonias. Las respuestas a preguntas personales derivadas de la inspiración no pueden ser cuestionadas más que por el derecho de un hombre a rezar por ellas. Todo esto está patrocinado en el templo, y coincide con muchos otros mormones que especulan y teologizan a nivel personal en las Escuelas Dominicales y las reuniones Sacramentales (Leone, 1974). Esto es interesante aquí debido al alto nivel de interpretación idiosincrásica garantizada a los mormones sobre asuntos espirituales. Este nivel de interpretación personal está precedido por la ambigüedad de la identidad del templo cuando uno se le aproxima, el silencio mientras uno está en él, el aislamiento con el propio pensamiento, el objetivo de las ceremonias para asegurar el pasado y el futuro, y la naturaleza altamente fragmentada y atomizada del edificio en sí mismo. Los mormones usualmente esperan tener una experiencia profundamente personal, espiritual y conmovedora en el templo.

Yo no argumentaría que lo que hacen los mormones al establecer significados personalizados es diferente en tipo de lo que hacen los estadounidenses en general, pero ciertamente es diferente en grado. La diferencia puede ser resumida arquitectónicamente cuando se compara el perfil del templo de seis espirales con el estereotipo de las iglesias americanas: la unidad del único capitel. La unidad, la integridad y la sencillez simbolizadas por la única torre en la iglesia Protestante Estadounidense contrastan tan claramente con el complejo de pináculos en el templo que el significado de esta imagen pública del mormón se resalta deliberadamente. Las torres tienen un significado iconográfico explícito en la medida en que representan las dos órdenes del sacerdocio mormón, cada una de las cuales tiene tres subdivisiones internas. Por supuesto, esto coincide no solo con las seis torres, sino también con su agrupación en dos conjuntos, con un conjunto más alto que el otro, lo que coincide con la importancia relativa de las dos órdenes. Cada conjunto de tres también se ordena en altura, por lo que también coincide con las calificaciones dentro de las dos órdenes del sacerdocio. A parte de marcar la masculinidad definida del edificio, las torres son un indicio de la compartimentación interna del edificio. No marcan una única unidad, sino una pluralidad de ellas. Esto no significa por inferencia que los Mormones tienen una teología no unificada o sintetizada de manera incompleta, pero sí significa que su método para llegar a la unidad está mucho más diversificado que en el Cristianismo Protestante estándar, y de hecho, dado que las seis torres representan a todos los hombres Mormones (quiénes son simultáneamente todos sacerdotes) versus, la única torre Protestante que simboliza la unidad de fe definida por sus teólogos, lo que tenemos en estos pináculos es un índice del hecho de que la teología está en manos de 
todos los adultos y que la fe es definida por todos Mormones. Por lo tanto, las muchas torres indican un potencial enorme de diversidad de significado dentro de la iglesia, así como la individualidad necesaria para lograrlo.

Los mormones han inventado un sistema muy difuso en el que cada creyente toma el mandato de la Reforma de que cada hombre sea su propio sacerdote y avance un paso más, es decir, que él también sea su propio teólogo. Este es un tema complejo que no puede ser desarrollado aquí excepto para decir que tal sistema de significados idiosincrásicos necesita un apoyo y un control cuidadoso. Su apoyo forma parte de los muchos entornos y prescripciones para discutir el significado de la fe en términos de problemas cotidianos. Forma parte de la manera en que el yo debe adaptarse al todo en el templo. La construcción personal de significado puede proliferar libremente solo si, además de alentarse, no se considera que esté en conflicto con lo que otros mormones creen o con otros segmentos de sí mismo.

La particularidad del templo y el prólogo de sus numerosas cámaras aisladas, en un sentido arquitectónico, ayudan a garantizar, de una manera determinista, la particularidad de las creencias que se pueden encontrar de mormón a mormón. Las categorías o compartimentos que existen en la visión del mundo de cualquier mormón y aquel que sostiene ideas incompatibles apartadas de éstas son todas permitidas aquí. Las ideas incompatibles surgen de cualquier sistema que implique juramentos secretos, conocimiento privado, revelaciones continuas y visiones del más allá. Se deriva de creer en el carácter literal Bíblico y en la revelación continua; de mantener supuestas actitudes raciales y respaldar los derechos civiles para todos; de oponerse a la biología evolutiva y creer en la evolución del conocimiento; de apoyar la prudencia sexual mientras disfruta francamente del sexo en privado. Esto equivale a decir que los mormones, como todos los creyentes, deben hacer malabarismos con las discrepancias y contradicciones, pero, a diferencia de la mayoría de los demás cristianos, deben hacerlo individualmente sin pensadores profesionales que inventen una síntesis para ellos.

El altamente compartimentado y muy comentado modo de pensamiento que resulta de esto se refleja tanto en el templo como en el patrocinio de la forma en que operan los rituales y el aparato del templo. El principio estructural, cognitivo o estilístico detrás de todo esto es: categorías cercanas pero mutuamente excluyentes. Como la forma medieval fue una forma apilada sobre una forma vertical, y el Renacimiento fue la simetría bilateral, el mormón es una real pero invisible contradicción. El modo de pensar de cualquier cultura obviamente debe consistir en categorías y oposiciones, pero es como ellas son combinadas lo que da lugar a las diferencias entre los grupos. Y más allá de eso, para muchas culturas, las categorías se tocan y se superponen, como fue el caso en la Edad Media (recordemos la casa medieval de Deetz) e incluso pueden considerarse bien integradas, como fue el caso del Renacimiento (la bien conocida idea del hombre del Renacimiento expresaba tal integración). Dicha integración no existe para los mormones o, si es así, sucede de una manera bastante inusual.

No solamente los mormones viven en un mundo de categorías, sino que esas categorías son de un tipo distinto. Para no ser demasiado esotérico o demasiado alejado acerca de eso, considero la siguiente cita.

La mayoría de los estadounidenses cree que el problema moral puede estar contenido dentro de una sola categoría, y a menudo se sienten asombrados o irritados por aquellos estadounidenses que no lo hacen. Muchos administradores de la universidad no pueden imaginar por qué los estudiantes que están recibiendo una educación liberal perfectamente pacífica deberían preocuparse por el hecho de que algún otro departamento de la misma institución realice investigaciones para el Departamento de Defensa. La mayoría de los estadounidenses no responsabilizan a un Rockefeller en Nueva York por el tipo de 
régimenque el banco de su familia ayuda a apoyar en Sudáfrica. Pero muchas personas negras y gente joven insisten en considerar todo conectado. Debido a que la Universidad Brigham Young, que es operada por la Iglesia Mormona, resulta ser uno de los pocos lugares en el país donde incluso los estudiantes creen en la santidad de las categorías, es difícil para casi todos allí comprender como la objeción hacia la creencia religiosa de un mormón puede ser traducida en violencia hacía el equipo B.Y.U. de baloncesto. Al reafirmar que las órdenes del sacerdocio, que todos los mormones varones deben cumplir para participar plenamente en la Iglesia, permanecerían cerradas a los negros, la Primera Presidencia declaró claramente no solo que el asunto estaba totalmente dentro de la categoría de religión, sino también que en la categoría civil la Iglesia específicamente enseña que todos los hijos de Dios deben tener los mismos derechos constitucionales. Además, el presidente de la universidad ha señalado que la Iglesia no tiene nada que ver con la organización de eventos deportivos; y, además, los entrenadores frecuentemente dicen, que algunos de los jugadores no son siquiera mormones, y el campo de atletismo obviamente no sería el lugar para discutir sobre política o religión, incluso si lo fueran. Sin embargo, los jugadores de baloncesto de B.Y.U. difícilmente puedan aparecer por algún lugar sin que sean silbados y considerados como racistas, y la Universidad de Stanford anunció el otoño pasado (1970) que ya no se reuniría con B.Y.U. en competencias atléticas. Manteniendo el argumento dentro de su categoría original, Ernest L.Wilkinson, presidente de B.Y.U., llamó a la acción de Stanford como "discriminación religiosa flagrante" (Trillin, 1970, p. 120).

Las categorías mormonas son excepcionales de dos maneras. Frecuentemente, como en el ejemplo citado, se encuentran en desacuerdo y resultan contradictorias con las categorías de la sociedad dominante y circundante. Además, ellas están, en un sistema que depende de la revelación para su lógica, frecuentemente en desacuerdo con ellas mismas. Esto no hace al sistema único, de hecho, probablemente explica su considerable fuerza, pero hace que la posición individual de cualquier mormón sea más sensible a los ajustes cognitivos que lo que exige el mundo a los estadounidenses comunes. Después de todo, nosotros, como nativos promedio de la sociedad dominante, no nos vemos obligados a comparar nuestras nociones con las de algún poder superior. Además, hay una gran cantidad de personas inteligentes cuyo trabajo consiste en arreglar de otro modo, cuando aparece, cualquier discrepancia y darle la forma adecuada. Lo que nosotros enfrentamos, como estadounidenses promedio, el mormón debe hacerlo individualmente. Él acaba desarrollando una gran capacidad para ello, se le da mucha práctica y en los ritos del templo se le muestra cómo mantener unido el mundo.

¿Qué categorías conflictivas traen los mormones al templo? Se alienta a los mormones a llevar sus problemas al templo, y algunos visitan el templo en tiempos de crisis personal. Todos esperan experiencias profundamente personales e integradoras allí. También hay otras expectativas. Originalmente, por supuesto, los mormones esperaban en un momento el milenio y, en cierta medida, todavía lo hacen. La crisis de ese noevento, así como de la persecución continua, también los llevan al templo. Entonces, hasta cierto punto, uno llega al templo con algo en mente. Hay que considerar, además, las presiones que sufre el mormón ordinario en su vida cotidiana, presiones no más agudas que las derivadas de tener que dar sentido al mundo dentro de una religión que es más pública sobre sus diferencias más espectaculares con Estados Unidos (anteriormente sobre la poligamia, ahora sobre el lugar del negro), y luego compararlas con lo que realmente sucede en las ceremonias sagradas.

La siguiente es una descripción general de las ceremonias extraída de varias fuentes.

El núcleo de los ritos implica un drama ritual. La creación del mundo y la "Caída” del hombre del Jardín del Edén, respectivamente. En la "Sala del Mundo”, los predicadores de Satanás son ridiculizados cuando presentan sus opiniones diabólicas...(luego) hay un reconocimiento de la restauración del "evangelio" a la tierra a través del profeta Joseph Smith. La culminación...ocurre en la "Sala Celestial" ("cielo") a la 
que se ingresa a través de un velo sagrado desde la "Sala Terrestre". Este velo es el último eslabón, o alternativamente el límite, entre el cielo y la tierra. El ritual [que dura aproximadamente tres horas] concluye con las ceremonias de "sellado" que unen a esposos y esposas o padres e hijos por un "tiempo" y por "la eternidad". Los ritos pueden ser tomados para la vida (de uno mismo) o para los muertos, en cuyo caso el individuo sirve como "representante" de un antepasado o amigo muerto en particular. En las etapas apropiadas a lo largo de los ritos, los diversos "grados " de los Sacerdocios Aarónicos y Melquisedec se otorgan a los participantes, quienes recitan juramentos bajo sanciones específicas de daños corporales que caerán sobre los infieles (Dolgin, 1974, p. 536).

El drama ritual que las personas ven es interpretado por funcionarios del templo quiénes representan a Adán, Eva, Lucifer, Jehová, Elohim, el Señor y varios apóstoles. Elohim es Dios el Padre, Jehová es Cristo, y el Señor, otra palabra para Dios el Padre. En el diálogo entre estas personas celestiales se establecen los actos ceremoniales claves (Whalen, 1964, p. 177-179). El diálogo entre ellos es un guion establecido, y es a la vez moderno y convincente. En el diálogo Adán, que representa al hombre, escucha a un típico predicador protestante exponer sus puntos de vista sobre el surgimiento de Lucifer. Adán encuentra las visiones, defectuosas, las rechaza y se describe a sí mismo como esperando que Dios lo ilumine verdaderamente. Este es un fragmento del drama que es seguido por más conversación entre los protagonistas quienes son básicamente Dios y el Diablo. La audiencia está representada por Adán y se le pide que se identifique con él, alguien quien espera, busca y se realiza. Esta parte particular del drama ritual enuncia el dilema que enfrenta cada mormón: cómo creer que lo que sabe es verdad mientras la mayoría de las personas con las que está rodeado en la vida cotidiana permanecen firmemente indiferente, por no decir contrarios a esto. ¿Cómo permanecer fiel y diferente?

Más tarde, en las ceremonias, justo antes de entrar en la Sala final o Celestial, el mormón individualmente se aproxima al velo que lo separa de la Sala Terrestre, es entrevistado por el Señor y le da la mano. El participante susurra su nombre secreto del templo en el oído del Señor y presenta los diversos signos de los sacerdocios que le fueron otorgados durante los ritos inmediatamente anteriores. Él luego cruza el velo, se une al Señor y entra al cielo en la Sala Celestial o Gloria. Para recordar una frase utilizada anteriormente de un mormón quien había pasado por el templo, "es como ir al cielo y volver de nuevo". Los mormones saben claramente que no han hablado personalmente con Dios ni han estado en el cielo, pero hablan como si hubieran experimentado algo bastante real, no un conjunto de metáforas elaboradas. ¿Qué significa el drama? ¿Cómo resalta el yo y su lugar en la familia eterna? ¿Y qué hace para permitir que un mormón viva exitosamente y feliz en un mundo tan en desacuerdo con su religión?

Yo pienso que el lugar para buscar una respuesta es en el análisis del mito de Lévi- Strauss (1963, p. 186205) en La efectividad de los símbolos. Lévi-Strauss cuenta cómo una mujer en un parto difícil fue tratada por un chamán quien le contó un mito de una lucha gigantesca, un relato que facilitó y liberó el nacimiento. LéviStrauss vincula la relación entre la mujer embarazada y el chamán con la de un paciente y un psicoanalista. El chamán invita a la mujer a ser absorbida por el mito, a experimentar el dolor genuinamente intenso pero anormal que está sintiendo, dolor que el chamán le dice que es parte de la lucha de los sobrenaturales elaborada en el mito. Al permitir que la mujer acepte y experimente plenamente el dolor, la tensión y la contradicción de su situación, el chamán facilita el nacimiento. Al escuchar el mito de la lucha violenta y gigantesca, una lucha que, según el mito, se está desarrollando en sus entrañas en este momento, la mujer puede dar libre desarrollo a los conflictos y resistencias inherentes a su situación y puede hacerlo en una manera que permita su resolución. 
Lévi-Strauss sugiere que todo esto es efectivo a pesar de que el papel del hablante se invierte, con el terapeuta hablando y el paciente escuchando.

Hay tres elementos involucrados en este análisis: (1) el individuo quien está experimentando algún problema, algún conflicto, (2) la recitación a la audiencia involucrada de un conflicto de importancia trascendente que se está desarrollando en este momento dentro de él o ella, y (3) una relación de transferencia entre el oyente y el hablante.

Reflexionando nuevamente sobre los ritos del templo, recordemos que los mormones ingresan al templo en dos condiciones simultáneas. Ellos van allí esperando una experiencia profundamente conmovedora, personal y satisfactoria. Cualquier mormón que ingrese al templo también enfrentará otros dos problemas; los cuales son su razón general para hacer la obra del templo. Él enfrenta el problema, al igual que toda su iglesia, de redimir a todas esas generaciones de la humanidad que vivieron antes de la "restauración del Evangelio", es decir, antes del advenimiento del Mormonismo. Este problema tiene dos facetas: ¿por qué la iglesia fue fundada tan tarde en el tiempo? ¿Y por qué las generaciones anteriores fueron excluidas de esto? Este es un problema acerca de cómo ver el pasado.

La segunda paradoja a la que se enfrenta cada mormón solo porque es mormón y, por cierto, porque también es cristiano, es el no-evento del milenio prometido. El profeta Joseph prometió sin ambigüedades la Segunda Venida antes de que la generación a la que estaba hablando falleciera. Los mormones tienen rienda suelta para sugerir cuándo volverá Cristo a la tierra y muchos esperan verlo en su vida. Sin embargo, Cristo no ha venido y la generación de Joseph ha fallecido. Ese problema es doblemente conmovedor porque la Segunda Venida establecería una dicha que mostraría tanto el triunfo de la iglesia como el fin de su persecución, siendo esto último algo en que los mormones aún insisten y de vez en cuando genuinamente experimentan. Que ellos puedan sugerirlo sin opinión puede indicar lo esencial que es la persecución para mantener las esperanzas milenarias.

La efectividad de recitar un mito sobre un futuro feliz a una congregación decepcionada en sus esperanzas milenarias han sido señaladas en un esclarecedor análisis realizado por John Gager (1975, p. 43-57) de ese texto bastante oscuro, el Libro de la Revelación, apocalipsis de San Juan. La narración del mito sobre el milenio a un grupo que lo espera inmediatamente permite al grupo, de acuerdo al uso de Freud por Lévi-Strauss, experimentarlo directamente y así resolver los conflictos entre la venida prometida y su incumplimiento, y entre la persecución continua y la dicha no conseguida.

Consideremos entonces lo que está sucediendo para el mormón en el templo. Él aporta expectativas de experiencia profunda y, a veces, problemas específicos para ser resueltos. Narrada ante él por personajes sobrenaturales está toda la historia humana que comprende la creación, la caída y la redención del hombre. En un momento, hay realmente un contacto verbal y físico con el mismo Dios y luego Dios invita realmente a los purificados a que entiendan y experimenten el cielo. A lo largo de las narraciones, la gente está escuchando a Adán, Dios el Padre y a Cristo hablar, no como lo lee un lector de los Evangelios, sino por personas que interpretan a los seres celestiales. Y para un impacto emocional adicional, la audiencia escucha conversaciones privadas fuera del escenario entre Dios, Cristo, Pedro y otros, haciendo planes para redimir al hombre basada en su actuación meritoria. Si él cree lo que está escuchando, el mormón está escuchando un nivel de realidad que no está presente incluso en las Revelaciones.

Las contradicciones entre el pasado y el futuro son superadas, y así consecuentemente el tiempo. El tiempo se detiene y todas las paradojas que surgen como resultado de la forma en que pasa el tiempo son 
enfrentadas y resueltas en la experiencia del templo, la cual es una recitación y promulgación completamente participativa y emocionalmente profunda de las respuestas a las preguntas básicas de la vida.

He sugerido dos conjuntos de problemas que cualquier mormón enfrenta cuando atraviesa el templo: el problema del pasado y el futuro, por un lado, y, por otro, problemas específicos que nosotros suponemos que se derivan de experimentar la arbitrariedad e incoherencia del mundo, especialmente cuando está en conflicto con el Mormonismo. El grado en que esto presiona conscientemente a un mormón debe variar mucho y es muy posible que la mayoría de los mormones ingresen al templo sin una conciencia específica de algún problema importante en particular. Sin embargo, cada mormón es consciente del hecho de que él es diferente de todos los demás estadounidenses y que esas diferencias, si bien son centrales para su religión y bienestar, son peculiares y frecuentemente invitan a la persecución. El mormón entonces atraviesa un ritual emocionalmente convincente que narra sus miedos básicos, el rechazo de su Padre, un mundo consecuentemente caótico, el tremendo poder de las tentaciones del mundo, el gran temor de que no pueda permanecer firmemente separado de ellas y los horrendos castigos que le esperan fuera de la fe. Él es invitado a reunirse con sus parientes muertos, permanente unión en la próxima vida con sus parientes más cercanos; él disfruta de la vista de Dios y entra en lo que solo puede considerarse como un anticipo de la dicha eterna. La totalidad de un conjunto de las más profundas crisis son enfrentadas por lo que ellos son, con todas sus implicaciones para que todos las vean.

El mormón llega al templo como miembro de una unidad familiar. Incluso si él lo atraviesa solo, está trabajando para sus parientes muertos, y finalmente entrará en la Sala Celestial junto con una mujer mormona, lo que significa que uno disfruta del máximo nivel de dicha celestial solo en conjunción con la propia familia. Solamente a través de su esposo puede una mujer disfrutar de esta exaltación definitiva y solamente con una esposa puede hacerlo un hombre. La unidad no es más grande que la familia y, aunque en teoría la familia incluye a toda la humanidad, el énfasis está en la familia nuclear. Y dada la naturaleza del parentesco, los lazos siempre se calculan a partir del yo, o del individuo, lo que significa que mientras la familia se unifica, el parentesco finalmente se atomiza. A cada persona se le da un nombre secreto en el templo que lo usa para identificarse ante el imitador de dios. Este nivel de individualidad que debe ser visto como importante permitiendo a un mormón resolver sus problemas individuales, resolver sus propias paradojas, para abordar lo que es peculiarmente incoherente y arbitrario en su propia vida, le es dado libremente en el templo. El individuo tiene tiempo para meditar, rezar, puede y a menudo tiene visiones, recibe revelaciones personales, y por lo que podemos juzgar de los mormones modernos y de las experiencias estáticas comúnmente atribuidas a la obra del templo en las vidas de Joseph y Brigham, puede disfrutar también de otros estados alterados de la conciencia. Creo que nosotros podemos asumir que la unión de los problemas generales y específicos encontrados en el templo ayuda a aumentar la experiencia que un mormón tiene allí, ya que él puede comprender los problemas generales a través de sus propios detalles y sus propios problemas en términos de la solución a los generales. Cada uno es esencial para resolver el otro.

El contexto del templo es uno de los varios contextos en los que un mormón puede resolver las paradojas creadas y resueltas a través de la manera en que él ve el mundo. Aquí él supera el tiempo para experimentar el pasado y el futuro, y supera el espacio para experimentar a las personas espirituales que habitan en otro mundo. $\mathrm{Al}$ experimentar tal fusión de categorías entre sí, el mormón puede tolerar la incoherencia y la arbitrariedad con las que vive a diario. Su propio modo de pensamiento parece ser el de aferrarse a nociones inconmensurables, nociones que son absolutamente esenciales para la existencia. La separación, aunque es 
parte de vivir una buena vida mormona, crea una tensión que es resuelta a través de los ritos del templo. La solución puede ser solo temporal ya que los mormones no pueden cambiar el mundo o su lugar en él. Tanto su lugar en él, uno subordinado, dada su condición de minoría religiosa y económica, como el éxito que han logrado en la explotación de su posición, ejercen cierta presión para mantener las cosas como están. Dado que los mormones son muy estadounidenses y muy mormones, y ser mormón es sospechar de Estados Unidos y ser ultra-americano, ningún mormón puede amar a su sociedad y rebelarse contra ella al mismo tiempo. Él está forzosamente dividido, vive en la sociedad pero aparte de ella; él debe vivir y pensar en categorías muy próximas pero completamente exclusivas. Y si las categorías no son mantenidas, su distinción es eliminada y su identidad junto con ella; también puede ser la pérdida de su capacidad para adaptarse a las demandas de ser miembro de una minoría, en resumen, su manera de ganarse la vida.

Ahora, reflexionando de nuevo sobre el templo, podemos ver que la experiencia relacionada con él mantiene a un hombre como un individuo completo al ayudarlo a resolver las tensiones de ser mormón, lo que a su vez le permite continuar usando las mismas categorías conflictivas que provienen de la vida cotidiana, categorías que hacen posible su participación en él en primer lugar. Toda esta categorización, las categorías muy cerradas pero excluyentes se ven en el aspecto físico del templo: los compartimentos, los pisos, los casilleros, los mapas iluminados que muestran cuáles de las muchas salas están en uso, la multitud de torres y el silencio. Toda esta planificación puede ahora ser comprendida en términos del principio estructural o cognitivo general que informa el Mormonismo; categorías cerradas pero mutuamente excluyentes. El templo aísla al individuo, resuelve ese aislamiento, pero lo hace solamente para sumergir de nuevo al individuo en él cuando terminan las ceremonias. Así, a diferencia de la psicoterapia y del mito del parto de Lévi-Strauss, el análisis de Gager de la función del Libro de Apocalipsis de San Juan para sus oyentes del primer siglo es más similar, la tensión se resuelve pero no se elimina: el futuro no puede ser realizado sino simplemente asegurado, o quizás vislumbrado.

Volviendo ahora un paso atrás fuera del mundo mormón y reflexionando sobre el diálogo ambiguo que establece el templo con sus espectadores aislados, a mí me gustaría explorar cómo el edificio y la manera en que es tratado mantiene la misma relación estructural básica en su conversación silenciosa con el mundo exterior.

El nuevo templo puede estar aislado creando una serie de oposiciones. El Templo de Washington, actualmente localizado a veinte o treinta minutos del centro de Washington, puede verse en relación con los otros monumentos religiosos nacionales en el área de Washington. Se puede comparar con la Catedral Nacional, que es Episcopal, y el Santuario Nacional, que es católico. Hay obviamente muchos otros, pero la comparación con estos dos será la cuestión. El Templo de Washington también se puede ver en contraposición con los otros Templos Mormones, principalmente con aquellos en la Gran Cuenca del oeste de los Estados Unidos.

Cuando comparamos el nuevo templo con los otros edificios religiosos nacionales en Washington, aprendemos que la Catedral Nacional fue iniciada en la década de 1880 y no fue terminada por más de otra década, que el Santuario Católico fue iniciado a principios de este siglo y todavía está siendo decorado, y que, a diferencia de esto, el Templo de Washington se inició en 1971 y estuvo completamente terminado en tres años.

La Catedral Nacional es un edificio gótico que se ha construido utilizando solamente material apropiado al estilo; no hay acero ni hormigón armado en él. El Santuario Católico es un edificio bizantino que también 
emplea tecnología que se considera apropiada al estilo. El templo mormón es completamente moderno. Estilísticamente está más cerca del Centro Kennedy para las artes escénicas y tecnológicamente es tan moderno como los mormones podrían hacerlo. Contiene 16.000 toneladas de hormigón armado.

La Catedral Nacional y el Santuario Católico estuvieron continuamente atormentados de problemas económicos. Los mormones recaudaron entre ellos al menos dos millones de dólares más de lo que necesitaban para pagar el edificio.

La Catedral, el Santuario y el Templo son todas atracciones turísticas. Todos ellos están ubicados en parques, dan la bienvenida al público en general, tienen recorridos y todos fueron construidos conscientemente para atraer tanto a los fieles como a los curiosos. En resumen, todos se usan a sí mismos como dispositivos misioneros. Pero a excepción de las seis semanas en las que estuvo abierto al público en general antes de su inauguración, el interior del templo mormón está cerrado a todos menos a los mormones dignos. Tú puedes caminar por él, pero no hay entrada.

¿Qué puede ser visto cuando el Templo de Washington es comparado con los templos de Utah? El Templo de Washington es el único al este del Mississippi, aparte de dos en Europa. Como la mayoría de los templos mormones que están en la Gran Cuenca, también se encuentran en los desiertos; desiertos suculentos para ser certeros, pero desiertos semiáridos de todos modos. El Templo de Washington está asentado en una exuberante ladera verde de Maryland sin otros edificios solo un bosque verde. Los templos de Utah siempre están en las ciudades. El Templo de Washington está en la ladera de una colina que da a la carretera de circunvalación, ruta 495, que transporta millones de automóviles anualmente por el norte y el sur alrededor de Washington. El Templo está aislado y no forma parte de ninguna comunidad visible; sin embargo es lo más visible sobre la carretera de circunvalación.

Todos los Templos Mormones están rodeados de exuberantes jardines; el jardín alrededor del templo en Washington está muy atenuado. Todos los templos de Utah son rectangulares; el Templo de Washington es hexagonal. Los templos de Utah tienen una o dos torres que no están coronadas con ningún símbolo. El Templo de Salt Lake tiene seis torres la más alta de las cuales está coronada por un ángel tocando una trompeta. El Templo de Washington, copia conscientemente al Templo de Salt Lake en este sentido, tiene seis torres, tres en cada extremo, y la torre más alta tiene un ángel tocando una trompeta en la parte superior.

Así, los mormones han construido un templo que conscientemente no está en un desierto, ni en una ciudad y no tiene un jardín real. Refleja sus principales símbolos visuales: la colmena, las torres del Templo de Salt Lake, el ángel trompetista, y se ubica sobre un acantilado con vistas al mundo que pasa. También es el templo más grande y el más caro de los dieciocho templos que los mormones han construido.

Todo lo que nosotros podemos concluir hasta ahora es que el Templo de Washington es una muy inusual iglesia nacional y un muy inusual templo mormón. ¿Qué están intentando lograr los mormones con este edificio? Hay que considerar los millones que conducen por la carretera de circunvalación. Y las 800.000 personas que lo recorrieron en las seis semanas entre principios de septiembre y mediados de octubre de 1974. Así como también que hay personas que permanecerán sin poder entrar nunca, dado que el edificio debe permanecer como un misterio. El templo comienza a verse como una prominente paradoja. Es asombrosamente visible; brilla y deslumbra sobre la carretera con sus torres doradas y paredes de mármol blanco. Y sin embargo es fundamentalmente distante. Su estilo es una mezcla fácilmente reconocible de un contemporáneo, Edward Durell Stone, art nouveau, DisneyWorld y un toque gótico. Es un pastiche factible de los clichés arquitectónicos de finales de los años sesenta y principios de los setenta. En resumen, es un edificio 
familiar y un edificio muy americano. Pero pertenece a un grupo de personas que todos los espectadores saben que solían ser polígamos y que hoy, según la perspectiva del espectador, son abiertamente racistas respecto a las cuestiones de los negros o simplemente son honestos sobre sus preferencias raciales. Ahora, ni la poligamia ni la exclusión de los negros son muy estadounidenses. Y, por lo tanto, hemos agregado a la paradoja de la alta visibilidad pero sin accesibilidad, la paradoja de un edificio estadounidense fácil de identificar construido por un grupo que ha sido y sigue siendo capaz de un comportamiento bastante no-americano. El templo se está convirtiendo en un edificio peculiar. Esto lo es aún más cuando el transeúnte se da cuenta de que piensa en el Mormonismo como una pequeña religión en algún lugar de Occidente. Y luego recuerda que la muerte de Dios fue proclamada hace casi una década. Sin embargo, paradójicamente, aquí hay una religión lo suficientemente saludable para construir un edificio de \$15.000.000 justo delante de sus propias narices. Estos son los obvios acertijos para ser leídos desde una visión no mormona del Washington Temple.

Para los mormones, este templo es el símbolo visible de su llegada a la costa Este, de su éxito en el centro del poder. Toda la visibilidad, el dinero y la velocidad en la construcción de las señales del templo son mensajes deliberados que los mormones quieren dar. Están llegando al poder y la prominencia nacional; son muy ricos, muy bien organizados y disciplinados. El templo, como dijo un mormón, "está construido para durar". También está construido para corregir - mejor dicho para cambiar - el estereotipo nacional utilizado para caracterizar a los Mormones. El templo no solo demuestra obviamente que la iglesia está viva, está bien, es grande, rica y poderosa, el mejor momento para los mormones, sino que dice también que los mormones están creciendo, son ricos y poderosos en el corazón del Este.

Además, ellos dicen que son cristianos. La pregunta que se hace con mayor frecuencia alguien que conoce a los mormones es: "¿Son ellos cristianos?, ¿ellos creen en Cristo?" La respuesta es inequívocamente sí - el nombre de la religión es después de todo La Iglesia de Jesucristo de los Santos de los Últimos Días -, pero es la pregunta, no la respuesta, lo que merece atención. Los mormones, como todas las minorías, viven bajo un estereotipo que se le impone sobre ellos y, como todos los estereotipos, son efectivos porque es creído por aquellos a quienes se les asigna. Los mormones se cuestionan a sí mismos porque han comenzado a creer que son lo que otros dicen de ellos. Los mormones reconocen que son ampliamente considerados como no cristianos y ellos intentan corregir esa mala impresión, destruir esa parte del estereotipo que limita algo de su libertad, exhibiendo prominentemente grandes cuadros o estatuas de Cristo en los recintos del templo.

Los mormones también saben que son fácilmente etiquetados como peculiares e incluso anti-americanos. Por esta razón, al igual que con el Templo de Salt Lake y muchos otros, el acceso principal tiene una enorme bandera estadounidense que ondea frente a las torres del templo. Esas torres alguna vez fueron el símbolo visible de todo lo que era fuertemente anti-americano dentro del Mormonismo y el espectador ahora solamente puede verlas dentro del contexto de la bandera nacional. Esta exhibición está destinada a decirle al espectador que esta iglesia es leal a Estados Unidos, y alude a la profundidad de su carácter estadounidense.

Usando dispositivos bastantes obvios como las representaciones estereotipadas de Cristo, las banderas estadounidenses y los estilos de construcción estadounidenses más puros, los mormones atacan dos de los errores más comunes utilizados para aislar en masa al grupo minoritario. El templo proclama que ellos son cristianos y estadounidenses e intenta cambiar el estereotipo.

Con datos de este tipo, nosotros comenzamos a ver que no estamos viendo solo un edificio religioso, sino también estamos viendo uno político. Y una vez que nosotros vemos esto, entra en juego todo un volumen de material. Los mormones consideran a su iglesia "como verdadera", fundada por Cristo usando a su profeta 
Joseph Smith Jr., ellos creen que la Segunda Venida tendrá lugar en América, y más precisamente en Independence, Missouri, que también fue el escenario del Jardín del Edén; sostienen que la Constitución de los Estados Unidos es de inspiración divina, y si no es un documento revelado como la Biblia, es el siguiente. Ellos sienten que la Segunda Venida es inminente y que será precedida por la decadencia y la caída de los gobiernos terrenales, incluido el nuestro. Nosotros no necesitamos insistir en la precisión de esa predicción, solo en el uso potencial que una religión milenaria puede hacer de ella. Los mormones sienten que en los días previos a la destrucción del mundo y la Segunda Venida, ellos y, más exactamente, su sacerdocio - cuyas órdenes están representadas en las seis torres del templo - salvará la Constitución manteniendo las riendas del gobierno después que un mal masivo haya corrompido el funcionamiento normal de los funcionarios. Visto bajo esta luz, el templo ahora se convierte no solo en una declaración política, sino que se ha convertido en el activo sitio de lanzamiento del milenarismo político. Esto forma parte de la ideología política expresada en términos teológicos que se representa en este templo. Es lo que se puede leer del edificio, conociendo la ideología mormona.

El Templo de Washington es un movimiento político diseñado para desafiar y cambiar las concepciones nacionales sobre los mormones. También es un recurso para hacer del Mormonismo una religión nacional. Cuando se ve como tal, nosotros podemos ver por qué es una iglesia nacional tan inusual, y un templo mormón tan inusual. Al ser el templo más grande y más caro, así como el templo más prominente que los mormones han construido, ellos anuncian su cambio hacia el este, fuera del desierto occidental. El templo anuncia sus ambiciones políticas tanto a los no-mormones del mundo como a ellos mismos. En este sentido, los mormones tampoco han construido un desafío para las iglesias nacionales, ni simplemente para otro templo mormón; ellos han construido un desafío para la capital nacional. Y en la medida en que nosotros vemos este artefacto ideológico como un edificio político en forma teológica, podemos comenzar a comprender su propósito más profundo. El templo es un desafío muy real y bastante concreto para la concepción actual de las cosas en los Estados Unidos, tal como los mormones piensan que las perciben.

Una cosa es anunciar un desafío a una visión dominante del mundo, y otra muy distinta es lograrlo. Pero al construir un monumento cuidadosamente concebido y ejecutado para acelerar los cambios políticos deseados, los mormones están actuando dentro de una tradición muy antigua y exitosa. Todos los grupos utópicos, incluidos los mormones en el siglo XIX, se propusieron modificar el comportamiento modificando el entorno físico en el que vivían los creyentes (Kanter, 1972, p. 74-126; Leone, 1972, p. 125-150). La construcción de un entorno físico cuya forma fue tanto habilitar como hacer cumplir el comportamiento y las actitudes deseadas está detrás de la tecnología sagrada que se encuentra en casi todas las utopías estadounidenses, y de hecho en casi todas las utopías del mundo occidental. Que esta tradición del siglo XIX, que fue una parte consciente del Mormonismo, se expresase en su templo más reciente, no sorprende.

Sin embargo, más que una tradición utópica de modificación del comportamiento a través del determinismo tecnológico está involucrado aquí. Cualquiera que haya caminado a través de la Basílica de San Pedro en el Vaticano entiende el principio de que el prestigio que una jerarquía religiosa quiere lograr puede alcanzarse construyendo un monumento a sí mismo. San Pedro del Vaticano comenzó su reconstrucción con el regreso del papado a Roma después del cautiverio babilónico en Aviñón. Fue un punto bajo en el poder y el prestigio del papado y coincidió con el anuncio de los planes para reconstruir San Pedro. El plan, por supuesto, aunque no se finalizó por completo durante dos siglos, celebró la posición central, la autenticidad y la gloria del papado. Esto no lo logró la antigua basílica construida por Constantino; pero se la construyó, como su 
predecesora sobre uno de los principales lugares de peregrinación de la cristiandad. Los papas combinaron el tráfico masivo de peregrinos con exposiciones arquitectónicas sobre su propia importancia para lograr un nivel de prestigio que nunca antes habían disfrutado.

Como un acto político, el templo mormón tiene dos distritos electorales: Mormones y no Mormones. Su efecto sobre los mormones es más preciso y calculado. El templo sirve a las decenas de miles de Santos en el este de los Estados Unidos, el este de Canadá y el Caribe. Dado que un mormón debe pasar por el templo una vez al año o más, el Templo de Washington reorienta el tráfico de peregrinación de hasta un tercio de un millón de mormones con todos los cambios económicos, políticos y emocionales que ello conlleva. Yo habría supuesto que tal reorientación habría fomentado tanto una integración más flexible de los santos orientales dentro de la iglesia en general, como una mayor independencia para este grupo tradicionalmente más liberal de mormones. Pero todos los mormones con los que hablé enfatizaron que el Templo de Washington los unió más estrechamente a la iglesia haciéndolos sentir como si estuvieran en igualdad de condiciones con los de Utah. Lo que parece estar detrás del sentimiento de mayor igualdad, y detrás de tener un templo también, es la noción de dar regalos como una forma de crear subordinación y socavar la independencia. Los mormones orientales han sido durante mucho tiempo problemáticos para la iglesia, que estaba feliz de tener un crecimiento en el Este, pero no estaba acostumbrada al grado de liberalismo y sofisticación que ese crecimiento particular trajo a la iglesia. Para esta población que frecuentemente se sentía distante y poco integrada dentro de la iglesia, la institución anunció que pagaría once de los quince millones de dólares necesarios para el nuevo templo. Este regalo fue recibido con una respuesta de los mormones orientales quienes recaudaron seis millones en lugar de los cuatro estipulados por Salt Lake. Esto tuvo dos significados a mi parecer. El primero es la gratitud espontánea por ser incluido en el rango de los mormones normales (teniendo un templo fácilmente disponible). El segundo, la respuesta devuelve parte del regalo de Salt Lake. Los regalos requieren reciprocidad creando una deuda. Al devolver parte del regalo, los mormones orientales mostraron que la iglesia subestimó su fuerza y lealtad, y mostraron también que una integración más cercana dentro de la iglesia significaba una pérdida de cierta independencia no especificada que era quitada una vez que el regalo era aceptado. Entonces, desde ambos lados, el templo como un regalo creará una comunidad mormona más unida: más cercanamente integrada en el Este porque ellos recaudaron mucho dinero y más cercanamente vinculada a la sede de la iglesia en el Oeste, ya que el templo fue un regalo abrumador y debe ser reconocido como tal.

El templo ayudaría al crecimiento y la visibilidad de la iglesia en el mundo exterior. El nombre de todos los que visitaron el templo fue anotado junto con una dirección. Los mormones planean que los misioneros visiten ese océano de 800,000 visitantes en el año y medio después de la inauguración. Aquí ellos están empleando una población autoseleccionada para aumentar la probabilidad de su propio crecimiento. Dado que un gran porcentaje de todos los mormones en el noreste han hecho su conversión en el pabellón mormón de la última Feria Mundial de Nueva York, el Templo de Washington representa el mismo modelo misionero en una escala más grande y permanente.

Cuatro de los quince millones de dólares que costó el templo se recaudarían de las áreas mormonas para las que se estaba construyendo el templo. En efecto, esto se refiere a los mormones de las ciudades de la costa este. Esto puede ascender a 40.000 mormones repartidos entre Washington, Nueva York y Boston. Este grupo relativamente pequeño recaudó al menos un 50\% más de lo que se les pidió que recaudaran. Los fondos generales del diezmo de la iglesia pagaron el resto del edificio, siendo esta la política habitual cada vez que es 
construido un templo o una sala de una capilla. Este hecho dice más de los mormones de la costa este que son personas exitosas que hacen grandes donaciones o grandes sacrificios a su iglesia.

La capacidad de recaudar enormes cantidades de dinero entre un grupo de personas quienes están dispersas y provincianas en relación con la fuente de poder produce alguna atención. Al hacer que muchas entidades hasta ahora autónomas dependan de una jerarquía organizativa, se crea un nuevo nivel de eficiencia. Es un error tomar un esfuerzo de construcción gigante como índice de coherencia política; es el medio para garantizar que el poder y la centralización seguirán, como fue el caso de San Pedro. Keynes llamó a esto un gasto deficitario, pero su propósito real es el éxito económico que se deriva de la organización requerida por un esfuerzo de construcción masivo (Mendelssohn, 1971, p. 210-220). Un trabajo como el Templo de Washington lleva el esfuerzo cooperativo y la eficiencia en la recaudación de fondos a un nuevo pico para los mormones en el este. La ejecución exitosa de tal labor equipara a las áreas mormonas con una maquinaria organizacional de un alcance y tipo diferente al que existía antes de la construcción del templo, y una capacidad de atraer a más conversos y de colocar a esos conversos en mejores trabajos como resultado de que más personas conocen los rasgos de comportamiento mormón, y de contar con más mormones para hacer la contratación. Con más y mejores trabajos, los mormones sienten que su religión es digna y verdadera y atribuyen la construcción de su comunidad y específicamente la de su templo a la Divina Providencia. Todo esto ilustra cómo la construcción del Templo de Washington afectó a cientos de miles de personas.

Después de demostrar que la construcción y el funcionamiento del nuevo templo realmente tienen un efecto concreto y real sobre la población no-mormona y mormona, y después de darnos cuenta de que este edificio bastante estático es de hecho bastante activo en términos de lo que su llegada y uso han organizado, es importante volver a las características más peculiares del templo: su aislamiento. Está cerrado, no está en el centro de Washington con los otros edificios religiosos nacionales, su arquitectura es peculiar. Es una paradoja masivamente confusa: no está identificado, su uso es secreto, es un imán cerrado en el sentido en el que atrae, pero no atrae hacia adentro; tienta pero no responde satisfactoriamente. Se ve muy estadounidense, pero representa una teocracia; enarbola la bandera pero el acceso no es democrático. El edificio como la religión y las personas que representa es estadounidense y mormón, similares pero no iguales, que vive en el mismo lugar y son miembros de la misma cultura pero no unificados; muy cerca, pero en última instancia, por deseo mormón y conformidad estadounidense, únicos. Entonces la estructura básica se repite, y lo hace mientras juega con algunas inclinaciones similares en la cultura estadounidense misma.

Pero la colocación del templo cerca de Washington, pero no en él, sugiere... impulsos para estar cerca pero no en la cultura principal. La idea del templo como cerrado al público [sugiere] que ellos están usando el impulso estadounidense para el descubrimiento, el éxito, el logro, el ascenso en la carrera como un señuelo olvidándose de las personas dentro de la iglesia en todos los sentidos de esa palabra. Aquí hay un secreto que todo estadounidense no puede tener: un club al que él debe unirse antes de ingresar. Tal mensaje tendría un atractivo especial para orientales adinerados y motivados por el éxito. Incluso la teología que proyecta tres niveles del cielo está en sintonía con la mentalidad de estatus y de ascenso en la carrera. En la misma línea, la idea de un secreto ha tenido un gran atractivo para los estadounidenses que viven en una sociedad que es supuestamente abierta y democrática. Aquí hay un grupo que admite que hay un secreto que guardar: ¿es el secreto de alguna manera su fanatismo? ¿Tiene la iglesia un atractivo especial para las personas blancas de clase media que son racistas de corazón pero quieren la conversión religiosa y la teología para justificar su racismo? Tales estadounidenses conservadores siempre saben... que el gobierno federal eventualmente hará que renuncien a otro verdadero ideal estadounidense a medida que el país pase de la tradición al comunismo (Elliott, 1975). 
El templo toma ventaja de una situación de tensión para comunicar su mensaje. Proporciona un esquema bastante pacífico y totalmente envolvente para el visitante no- mormón que se encuentra junto a la carretera de circunvalación. Al hacer el recorrido por el centro de visitantes y los jardines, a los que cualquiera es bienvenido, uno se enfrenta a las promesas que ofrece el Mormonismo, y a la negación de vislumbrar cómo se ve la paz y la coherencia en el interior del templo. El estadounidense puede acercarse pero no cruzar. Él está confrontado con la estructura básica de la visión del mundo mormona: no se puede ser estadounidense y mormón, los dos deben permanecer distintos para que este último continúe existiendo. Las dos categorías deben existir pero no cruzarse ni mezclarse. Solo de esta manera puede el mormón, a sus propios ojos, ayudar a mostrarle a Estados Unidos el camino. Y solo de esta manera puede Estados Unidos continuar haciendo uso de la minoría mormona. El turista casual es el converso potencial, pero él tiene que haber estado en desacuerdo con su propio sistema antes de que las paradojas destacadas por el templo mormón lo golpeen y le permitan apreciar las resoluciones que le esperan dentro del Mormonismo. El tema básico del templo, según los mormones, es la alegría. Los mormones no dicen la alegría no puede ser experimentada sin el dolor precedente; pero han ubicado al templo de tal manera que lleva al visitante receptivo a una máxima confrontación con cómo es de insatisfactorio el mundo tal como él lo está experimentando actualmente.

El mormón también, como todos los demás, experimenta dolor en forma de problemas de la vida cotidiana. Pero al ayudarlo a resolver el dolor, para lo cual es la experiencia del templo, ayuda al creyente a aceptar la profundidad del mismo. Al hacerlo más consciente y al compartirlo con otros, los ritos del templo le dan significado, lo organizan y, en consecuencia, lo alivian. Pero a causa de la estructura del mormonismo, el dolor nunca puede ser resuelto o finalmente eliminado. La estructura insiste en la separación y puede solamente relajar la tensión resultante. Y la tensión debe permanecer debido a la estructura del Mormonismo.

Es apropiado preguntar qué trajo tal estructura a la existencia y qué la hace continuar. Yo pienso que la respuesta a estas dos preguntas mostrará por qué la paradoja de su estructura no puede ser resuelta. Los orígenes históricos de las categorías cercanas pero no superpuestas se encuentran en la historia utópica del Mormonismo del siglo XIX, una historia compuesta de una larga lucha, característica de las utopías americanas, entre la eliminación y la alienación de la sociedad parental por un lado, y un plan, por el otro, para mostrarle al mismo padre un camino hacia una versión mejor y más perfecta de sí mismo. Los mormones estaban en rebelión, pero no tenían la intención de ser independientes. Al intentar empresas cooperativas, nuevas relaciones familiares, revelación directa a un profeta y un gobierno teocrático, los mormones intentaron resolver muchos de los males sociales comunes al temprano Estados Unidos industrial y a Europa occidental. Estos experimentos los llevaron a la persecución por sus esfuerzos y forzaron a los mormones de Nueva York, Ohio, Missouri e Illinois a trasladarse finalmente a la región completamente vacía de la Gran Cuenca y a Utah. Conducidos cada vez más lejos de Estados Unidos con todos los esfuerzos para mejorar la vida dentro de él, ellos no querían ser menos que ciudadanos estadounidenses. Para los mormones, la Constitución de los Estados Unidos siguió siendo un documento divinamente inspirado y los mormones de Utah intentaron obtener la condición de estado muchas veces antes de alcanzar el éxito en 1896. Todo esto y mucha más información apoya la tensión histórica básica que surge de querer perfeccionar a Estados Unidos, querer estar separado de él, siendo perseguido por él y nunca siendo independiente de él. A lo largo del siglo XIX, los mormones estuvieron dentro y fuera de la sociedad estadounidense al mismo tiempo: en rebelión, pero para ser una vanguardia. Desde 1847 cuando ellos entraron en Utah, hasta 1896 cuando obtuvieron la condición de Estado, la población mormona estuvo hasta cierto punto realmente aislada del resto de los Estados Unidos. Durante la 
primera parte de ese período, los mormones eran casi independientes políticamente, lo que significaba que la diferencia entre ser mormón y ser estadounidense no era fuerte, y significaba, además, que en aislamiento las diferencias que caracterizaron al Mormonismo pudieron e incluso han estado bien desarrolladas.

Con la activa campaña del gobierno federal contra el matrimonio plural en las décadas de 1880 y 1890 , con la categoría de Estado y con el desarrollo económico del área por parte de ferrocarriles no-mormones, minas, madera e intereses agrícolas, surgieron dos fuerzas para cambiar, o quizás mejor, para resaltar la naturaleza de la relación del Mormonismo con el país en su conjunto. Una gran y ruidosa población antimormona se introdujo en el Estado, y en segundo lugar, la capital del Este poseía su economía al mismo tiempo que las agencias federales reemplazaban las instituciones económicas de la iglesia que previamente habían asegurado la autosuficiencia económica del área. Por lo tanto, en 1900, Utah fue reducida de la autosuficiencia económica a la dependencia colonial. Mientras que tempranamente fue posible ser mormón y estadounidense porque los peores aspectos de este último no entraban en el aislado Utah, ahora con el comienzo del siglo XX, fue necesario llegar a un acuerdo que permitiese vivir tanto en el mundo mormón como en Estados Unidos y hacerlo simultáneamente y de manera muy cercana.

Los mormones comenzaron a vivir en un entorno económico donde ellos estaban en competencia con otros Anglos, Chicanos y varios grupos de Indígenas Americanos. Además, ellos habían perdido el control sobre su economía. Este conjunto de circunstancias produjo una población que responde al máximo al cambio externo y que, como resultado, se ha vuelto muy exitosa en explotar su propia situación colonizada. "Los mormones son los mejores segundos comandantes del mundo" personifica la visión del mundo mormón que ha evolucionado a lo largo del siglo XX. Yo he detallado en otra parte (Leone, 1974) cómo trabajan los procesos de adaptación al cambio rápido y la racionalización de la flexibilidad. Pero aquí es seguramente suficiente decir que lo que nosotros vemos es a estas personas viviendo en un mundo de alta ambigüedad, incoherencia y arbitrariedad. Viven en él de tal manera que explotan sus características y construyen el éxito al utilizarlas. Los mormones pueden hacer esto manteniendo el mundo dividido en categorías - pero categorías especiales - cuyas contradicciones no intentan resolver, sino que las aceptan. Esto significa que rara vez tienen que molestarse en sintetizar numerosas contradicciones, sino más bien arreglarlas de otro modo a voluntad.

Por fascinante que esto suene, yo pienso que también es correcto, y solo puede ocurrir frente a una ceguera casi total de lo que está sucediendo. Probablemente la característica más notable de un mormón cuando lo conoces es su certeza. El no solamente "sabe" que su iglesia es verdadera y que Joseph ha sido un profeta de Dios, sino que está seguro de que comprende de qué se trata la vida, su lugar en ella y su rol en el pasado y el futuro. Él tiene las respuestas, y realmente las tiene. La producción de esas certezas son las experiencias e instituciones como el templo que toma las categorías con las que vive un mormón, las llama verdaderas, necesarias y dolorosas; muestra la dicha que proviene de ser valiente frente a ellas; les quita el miedo sumergiéndolos en ellos dentro del templo; y luego envía al individuo de regreso para comenzar de nuevo.

\section{AGRADECIMIENTOS}

Estoy particularmente en deuda con los profesores Jean-Paul Dumont, Emory Elliott y James Boon por sus largas conversaciones sobre la esencia y la teoría de este artículo. El profesor John Gager aclaró puntos en su propio trabajo para mí. Los profesores Charles Peterson y John Sorenson leyeron los borradores de este 
artículo e hicieron valiosos comentarios al respecto. Estoy en deuda con George S. Tanner y Robert L. Schuyler por su ayuda para evaluar la sensibilidad de parte del material de este artículo. Alfred Bush hizo correcciones muy importantes sobre el lugar del individuo en los ritos del templo. Una conversación útil con Lewis Binford en el momento en que este artículo fue leído me permitió tener en mente cuánto se aparta este trabajo de la epistemología positivista.

David y Janice Allred y David Tolman respondieron pacientemente mis preguntas sobre el templo y me enseñaron su importancia para los mormones. Estoy agradecido con ellos.

Las impresiones de primera mano del Templo Washington fueron reunidas durante un recorrido en septiembre de 1974 mientras el edificio estaba abierto al público.

El permiso ha sido otorgado por The New Yorker para la cita de Calvin Trillin.

\section{REFERENCIAS BIBLIOGRÁFICAS}

Deetz, J. F. (1974). A cognitive historical model for American material culture, 1620-1835. In Moore, C. B. (Edit.), Reconstructing complex societies. Supplement to the Bulletin of the Schools of American Research, No. 20.

Dolgin, J. (1974). Latter-day sense and substance. In Zaretsky, I. I., \& Leone, M. P. (eds.), Religious movements in contemporary America, Princeton University Press.

Elliott, E. (1975). Personal letter of June 17.

Gager, J. G. (1975). Kingdom and community, the social world of early Christianity. Prentice Hall, Inc.: Englewood Cliffs

Kanter, R. M. (1972). Commitment and community, communes and utopias in sociological perspective. Cambridge: Harvard University Press.

Leone, M. P. (1972). Archaeology as the science of technology: Mormon town plans and fences. Research and theory in current archaeology, New York: C. L. Redman editor. Wiley-Interscience, John Wiley and Sons.

Leone, M. P. (1974). The economic basis for the evolution of Mormon religion. In Zaretsky, I. I., \& Leone, M. P. (eds.), Religious movements in contemporary America, Princeton University Press.

Levi-Strauss, C. (1963). The effectiveness of symbols. Structural anthropology. New York: Basic Books.

Mcconkie, B. R. (1966). Mormon doctrine. Salt Lake City: Bookcraft.

Mendelssohn, K. (1971). A scientist looks at the pyramids. American Scientist (59), p. 210-220.

Panofsky, E. (1955). Meaning in the visual arts. Garden City: Doubleday and Company, Inc.

Rowe, J. H. (1965). The renaissance foundations of anthropology. American Anthropologist (67), p. 1-20.

Thillin, C. (1970 March 20), U. S. journal: Provo, Utah, categories. The New Yorker, New York.

Whalen, W. J. (1964). The Latter-day Saints in the modem day world. Notre Dame: University of Notre Dame Press. 